Article

\title{
Is the High-Density Housing Layout Affected by River Direction? Lessons from Seoul, South Korea
}

\author{
Youngsang Kwon *, Youkang Seo * and Jihyun Hwang \\ Department of Civil and Environmental Engineering, Seoul National University, Seoul 08826, Korea; \\ superior1412@naver.com \\ * Correspondence: yskwon@snu.ac.kr (Y.K.); youkang1002@snu.ac.kr (Y.S.); \\ Tel.: +82-2-880-8200 (Y.K.); +82-2-880-7374 (Y.S.)
}

Received: 19 December 2018; Accepted: 23 May 2019; Published: 28 May 2019

\begin{abstract}
This study analyzes apartment building configurations in waterfront residential areas relative to water flow direction and assesses the waterfront impact on apartment construction planning. It surveyed 197 apartment buildings around Yangjaecheon, Gulpocheon, and Anyangcheon, three branches of the Han River, a major South Korean river, to ascertain the correlation between stream flows and apartment building configurations. The apartments were classified into four spatial-configuration categories relative to the adjacent stream's flow axis-perpendicular, parallel, diagonal, and other-and three orientation categories—east- and/or west-facing, south-facing, and other. South-facing apartments were predominant around west- and north-flowing streams. The proportion of east- and/or west-facing apartments built and the percentage of south-facing apartments were relatively low, indicating that apartment building layouts are more diverse around north-flowing streams than around west-flowing streams. A t-test analysis of east- and south-facing apartments' proportions relative to stream flow direction was statistically significant, and there were relatively higher percentages of east- and west-facing apartments near north-flowing streams than west-flowing ones. This suggests that the relationship with rivers is still important in urban housing in South Korea, and the importance of landscapes over the river is of increasing significance for planning urban settlements.
\end{abstract}

Keywords: high-density housing; apartment; riverfront; waterfront; apartment building layout

\section{Introduction}

\subsection{Human Settlement and Waterfront}

Throughout the history of mankind, prominent cities of antiquity, where human settlement flourished, have been formed around waterfronts. Therefore, waterfronts have been closely related to urban space. Proximity to waterfronts has affected the economic development, social composition, and cultural formation of the cities that formed in the surrounding waterfront areas. These spaces have served as a driving force of urban growth, serving as harbors as well as sources of water for industrial use, and are considered valuable spaces for sustainable urban development [1,2]. Particularly, as waterfront areas provide a large, open, public space and create an open landscape, they have offered great opportunities for conducting cultural activities, providing amenities, and ensuring appropriate environmental conditions in recent decades [2-4].

Korea has traditionally considered the relationship with rivers as an important factor in determining the environmental condition of human settlements. This has been the case in many Asian countries, including China, which accept the concept of Feng Shui. In the later urbanization process, although high-density housing became a common type of residence, the relationship between the residence and 
the river was still an important factor. Traditionally, in the case of east-west rivers, in order to face the rivers, residences were planned and developed as south-facing ones, thus fitting the concept of Feng Shui, which is preferred by South Koreans. However, in the case of north-south rivers, in order to face the rivers, west-facing residences had to be developed, which do not fit the Feng Shui concept.

Many South Korean cities are situated near rivers due to the landscape consisting of many rivers and mountains, as well as the practice of geomancy [4]. The Han River passes through Seoul, the capital city of South Korea, and it has played an important role since ancient times. Since 1950, the expression "miracle on the Han River" has been used to symbolize South Korea's economic development. Recently, the "Han River Renaissance Project," which aims to revitalize Seoul's urban space centered on the Han River, was launched [5] (see Figure 1).

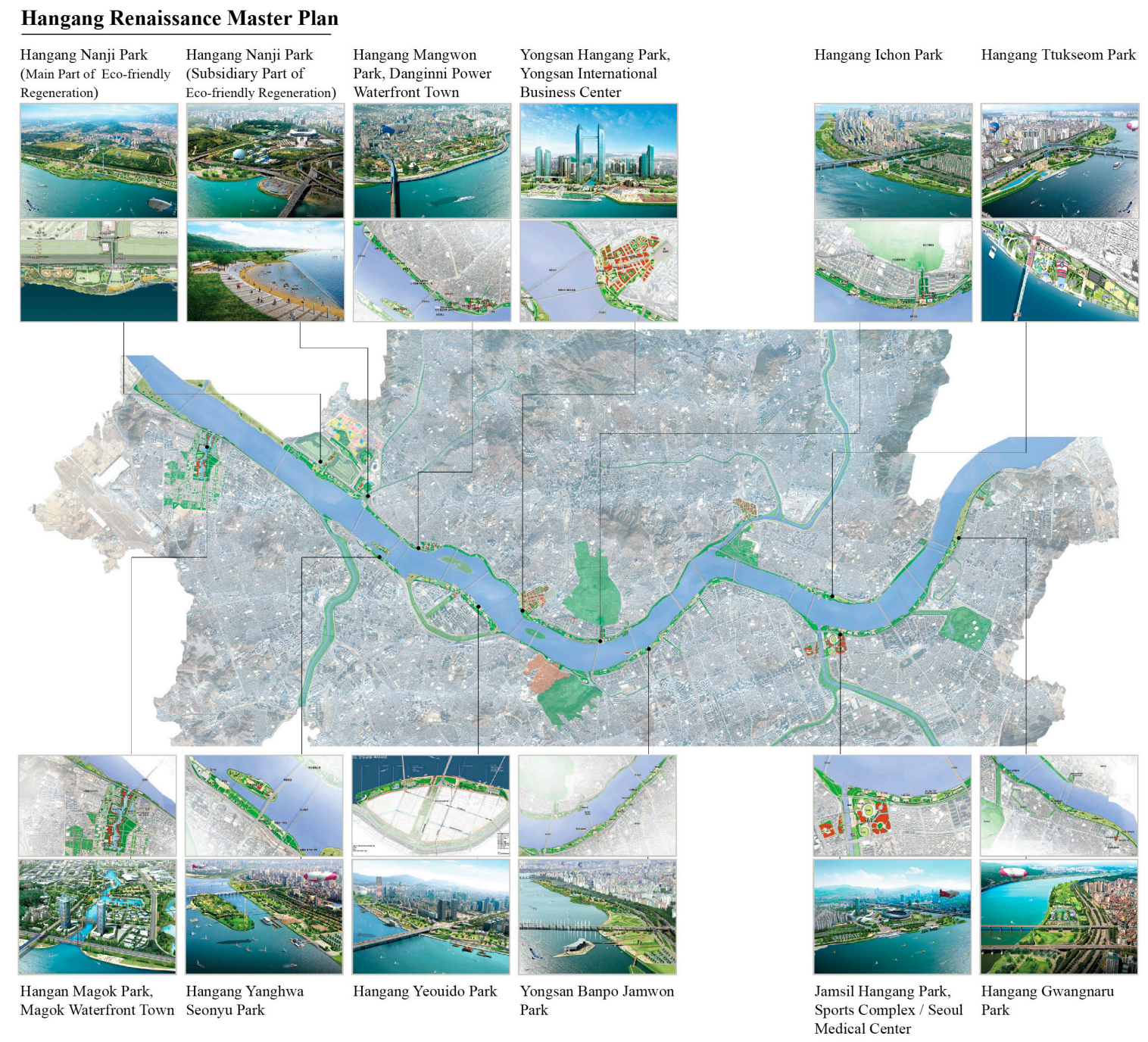

Figure 1. Hangang Renaissance Master Plan (Source: City of Seoul).

The Han River passes through central Seoul, and it flows from east to west with various branches, such as the Jungrangcheon, Anyangcheon, and Tahncheon streams. Additionally, Han River Park, which has been developed along the Han River, provides an excellent recreational place for Seoul's residents. Research on how the waterfront is used by residents found that the waterside environment has a major influence on the assessment of the quality of the surrounding residential areas [6].

In the 1970s, the south side of the Han River was developed in earnest, and most dwellings were newly developed. During this process, all new dwellings were developed as high-density apartments. In particular, most dwellings developed on the riverside were high-rise apartments, which became 
the preferred housing type for development at the time because they offered riverfront scenery and a congenial environment (Figure 2).

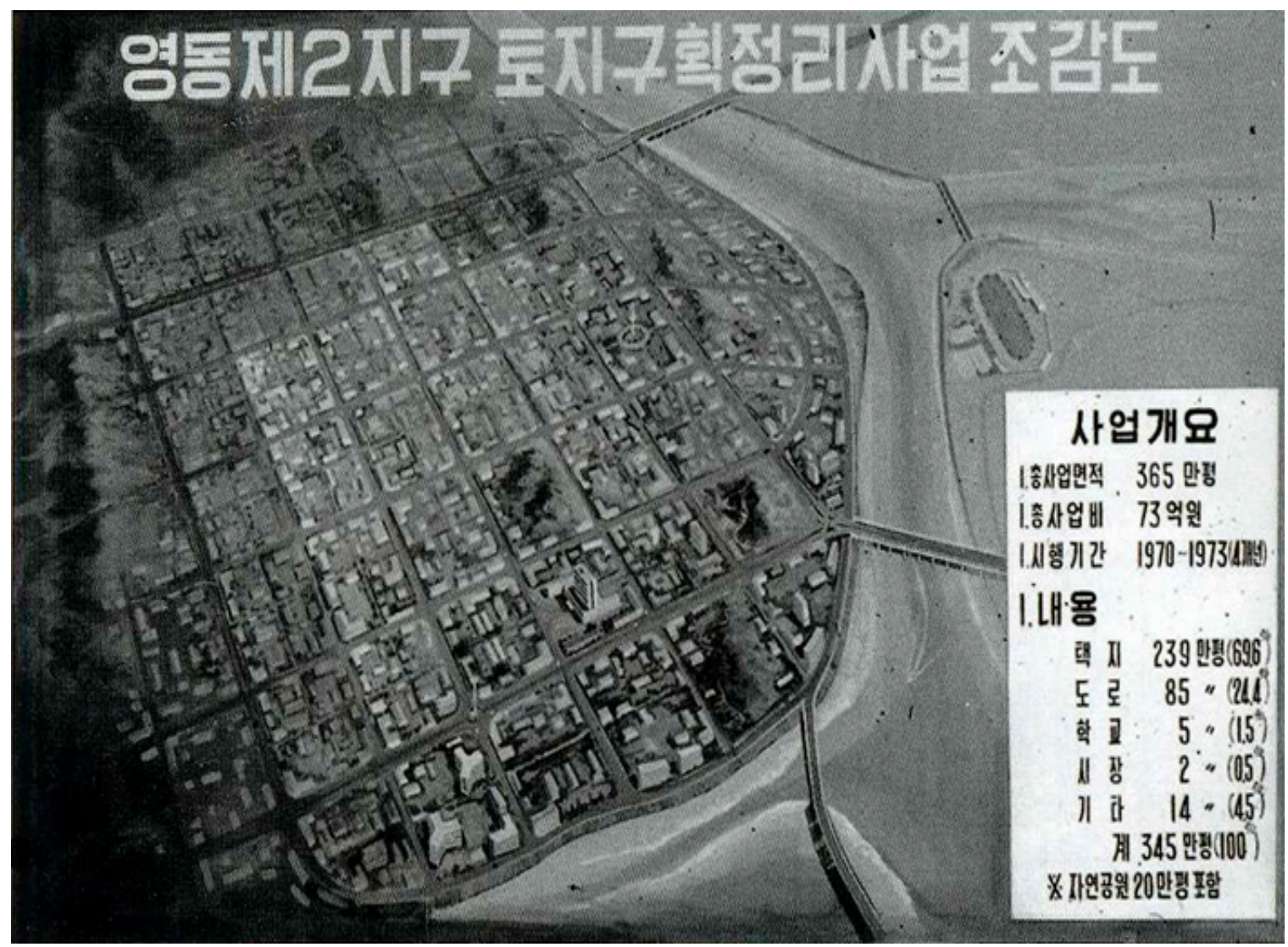

Figure 2. Southern Part of Seoul (Gangnam) Development Plan (Source: City of Seoul).

Recent surveys on waterfront views afforded by waterfront apartment complexes have collected residents' opinions on the urbanness, habitability, and design quality of waterfront areas. These provide base data for analyzing and understanding resident attitudes toward the waterfront; attitudes which are crucial for developing landscape plans [7].

\subsection{Study Purpose}

This study aims to analyze how the spatial relationships between apartment buildings and adjacent streams influence the apartment building layout. Originally, the preference for residences on the south side was evident in the housing prices, including those of apartments, in South Korea [8]. Although most South Koreans still prefer south-facing apartments and residences, different apartment types and configurations are being adopted in accordance with the abovementioned factors. Recently, a growing interest in landscape and waterfront views has brought changes to the type and configuration of apartments being built along the waterfront. In residential areas close to streams and other water bodies, factors such as landscape and views are especially likely to influence the configuration of apartment buildings. However, few studies have examined the characteristics of residential spaces in South Korea in terms of their spatial relationships with streams.

In this study, we hypothesized that housing layout would vary, depending on the direction of the river. As previously suggested, traditionally southward-facing residences have been preferred by South Koreans. However, if a stream flows in the east-west direction, apartments designed to have waterfront views can still have a good view of the river, heading south. On the other hand, if a river flows in the north-south direction, apartments seeking waterfront views will not be able 
to view the river as it heads south. Therefore, when a stream flows north-south, it is necessary to decide whether apartment arrangements should follow traditional residential preferences for the south, or the view of the landscape and waterfront view. This study found that the ratio of eastand westward-facing residences close to the river flowing in the north-south direction is relatively higher than those next to the river flowing in the east-west direction. This shows that, contrary to the traditional housing arrangement featuring southward-facing residences, river view and landscape are increasingly important factors to consider when examining housing arrangement patterns.

\section{Riverfront and Apartment Housing in South Korea}

\subsection{Apartments in South Korea}

As apartment buildings are the predominant type of housing in South Korea, many studies have been conducted on this topic [9-11]. Research by the Korea Statistics Authority in 2010 showed that apartments represent $60 \%$ of South Korea's housing system [12].

In the 1950s, rapid urbanization and population growth caused a housing shortage in South Korea. However, since the 1960s, Seoul has become progressively urbanized; thus, Seoul's urban landscape changed during the intervening period. Jongam Apartments, the first apartment complex in Korea, was constructed in 1958, and numerous new apartments were built in the 1960s and 1970s on the slopes in the periphery of downtown Seoul, as well as on the riversides north and south of the Han River. Notably, large-scale apartment complexes sprang up in the 1970s in Gangnam, the area south of the Han River, as part of efforts to curb growth in Gangbuk, the area north of the Han River [12]. As a result, Gangnam became the most popular site for speculative real estate investments in the 1980s; recently, it has become a geographical and symbolic center of wealth in South Korea, with a concentration of high-end, mixed-use buildings [8]. Around the same time, the Banpo Apartment Complex and mega-apartment complexes in Jamsil were constructed, marking the beginning of intensive development in the Gangnam area [12] (Figures 2 and 3). In the process of South Korea's rapid economic growth, which was dubbed "the Miracle on the Han River," a large number of apartment complexes were constructed on the northern and southern riversides of the Han River. Following the success of the apartment complexes in Jamsil, apartments began to be regarded as housing for the middle and upper classes [13], which helped to bring about a boom in apartment construction along the Han River. Large-scale apartment complexes such as Apgujeong Hyundai, Hanshin, and Gyeongnam were constructed around this time [9]. Consequently, the proportion of apartments compared with other types of housing skyrocketed in the area south of the Han River, and the nationwide percentage of apartments also increased. In 1975, the total number of apartment units amounted to 89,248 , but the figure jumped to 8,185,063 in 2010 [9] (as shown in Table 1). The Korean government has devoted immense efforts to developing policy that increases the housing supply through new town development, residential land supply, and urban redevelopment. As a result, the housing supply ratio, which was $86 \%$ in 1995, exceeded $100 \%$ in 2002 and reached $118.1 \%$ in 2014 [9] (Figure 4). These figures reflect the fact that, since 2002, the housing supply has exceeded the total number of households in South Korea.

Table 1. Number of apartment units (1975-2010).

\begin{tabular}{lcccccccc}
\hline \multicolumn{1}{c}{ Year } & $\mathbf{1 9 7 5}$ & $\mathbf{1 9 8 0}$ & $\mathbf{1 9 8 5}$ & $\mathbf{1 9 9 0}$ & $\mathbf{1 9 9 5}$ & $\mathbf{2 0 0 0}$ & $\mathbf{2 0 0 5}$ & $\mathbf{2 0 1 0}$ \\
\hline $\begin{array}{l}\text { No. of } \\
\text { Apartment units }\end{array}$ & 89,248 & 373,710 & 821,606 & $1,628,117$ & $3,454,508$ & $5,231,319$ & $6,626,957$ & $8,185,063$ \\
\hline
\end{tabular}

Source: KOSTAT (2010), Housing census. 

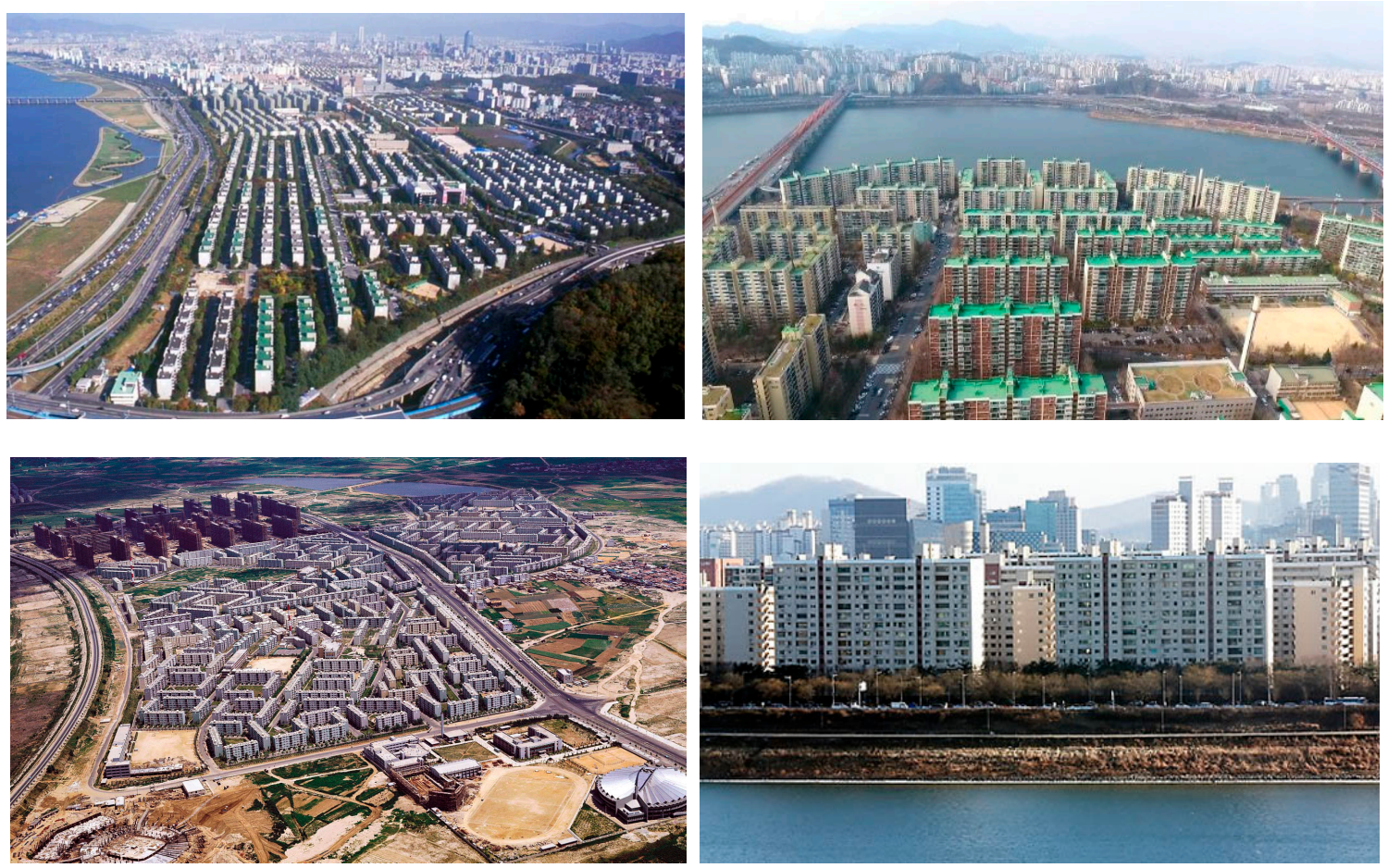

Figure 3. South Korean Apartment built in 1970s near Hangang River, Southern Part of Seoul (Gangnam) Banpo Apartment [up-left], Apgujeong Apartment [up-right], Jamsil Apartment [down-left], and monotonous facade of South Korean Apartment built in 1970s [down-right].

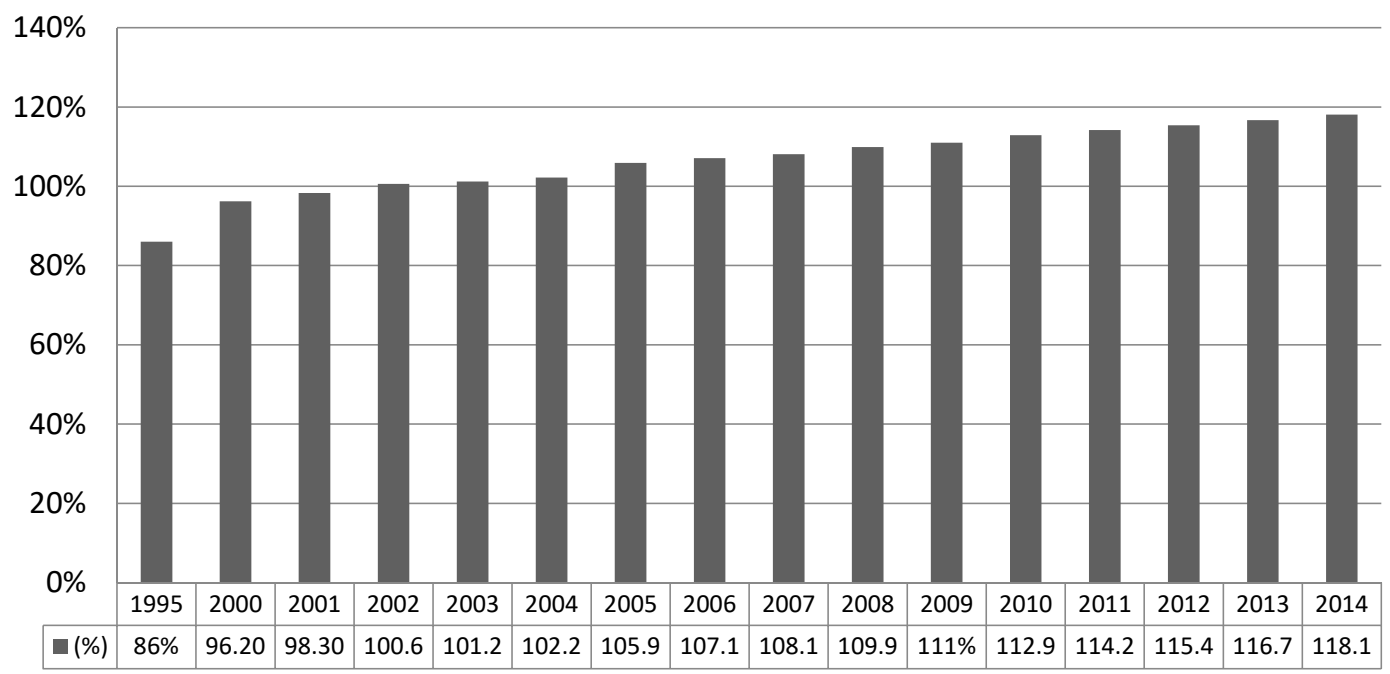

Figure 4. Housing supply ratio (\%) (1995-2014). Source: KOSTAT (2015), Housing census.

Unique urban forms and landscapes began to appear as apartment complexes were enlarged, and various other types of multi-dwelling units were constructed in large quantities [13-15]. In the 1950s, most housing units in Seoul were detached houses, forming a low skyline. However, the beginning of development in the Gangnam area in the 1970s raised the skyline and gave birth to an urban landscape featuring apartment buildings standing in parallel [13] (Figures 2 and 3). However, the apartments, which were built in the 1970s, have been criticized for their monotonous and characterless appearance. At that time, apartment complexes were arranged in a repetitive manner, with each apartment building duplicated in the same form (Figure 3, [bottom-right]).

To address these problems of marring the landscape and blocking the visual corridor, apartment buildings began being built in a new diagonal configuration, as with the Jamsil Apartments, or in cluster formations around a square-shaped center. One study examined how buffering structures or 
green spaces are created in waterfront areas to slow the inflow of water in the case of flooding, with various configurations adopted with respect to the sides of buildings facing the waterfront to alleviate the impact of inflowing water [16]. The relationship between apartment alignment and a river can be categorized as perpendicular, parallel, diagonal, and other (Figure 5).

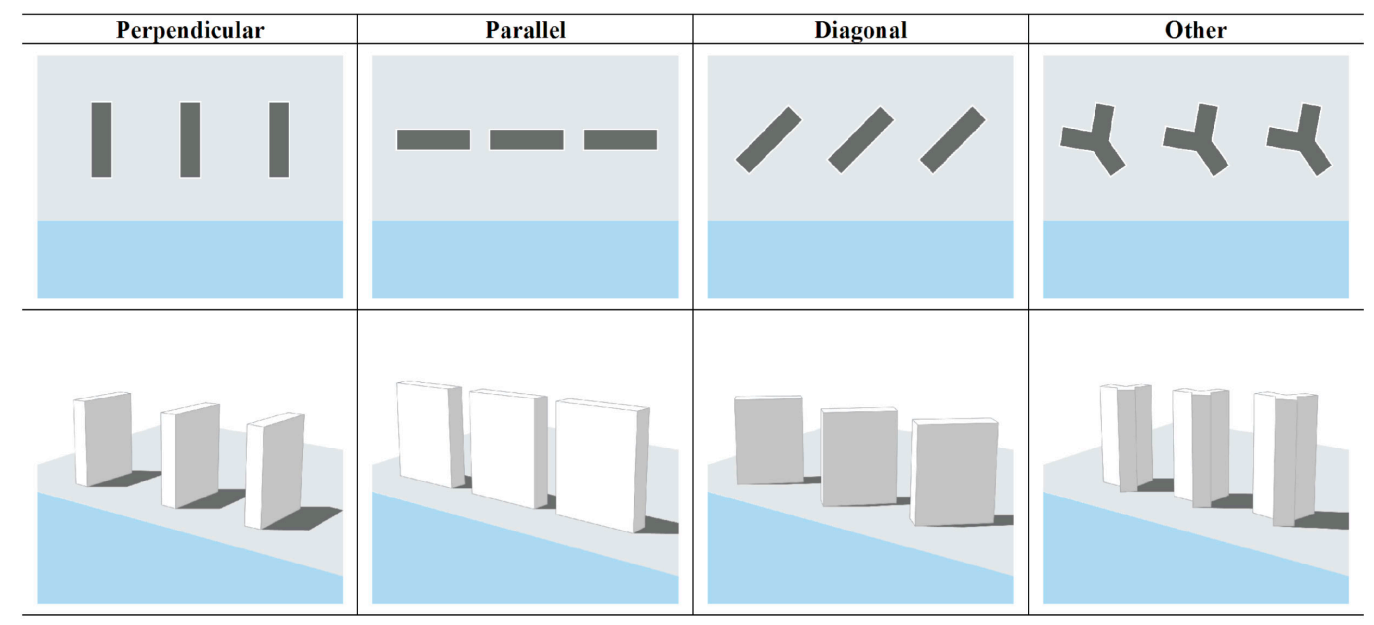

Figure 5. The relationship between apartment alignment and a river.

\subsection{Housing Orientation in South Korea}

Another housing characteristic of South Korea is a focus on southern exposure and preference for southward-oriented houses. The reason for this is the availability of sunshine and influence of geomancy. Such residential preference has a long history in South Korea, and the appearance of traditional Korean housing reflects this preference of some South Koreans. Similarly, the building of settlements facing streams is also traditional, as the concept of Feng Shui is commonly used in Asian countries (Figure 6). According to Feng Shui, places with mountains in the rear and a river in the front are seen as suitable for residences. Mountains behind a residence are advantageous in that they block cold air from the north, while rivers supply residents with fertile soil and water. This arrangement is depicted in the " 4 " area in Figure 6. Thus, south-facing settlements allow residents to see the beautiful hills and the river in front (" 5 ", "10", “11").

1,2 Ancestral dragon mountain

3 Main dragon mountain

4 The site is broad, level, and rectangular

5 The river in front curves like a band

6 East mountain

7 West mountain

8 Protective hills

9 Water-mouth

10 The table hill

11 The facing hill

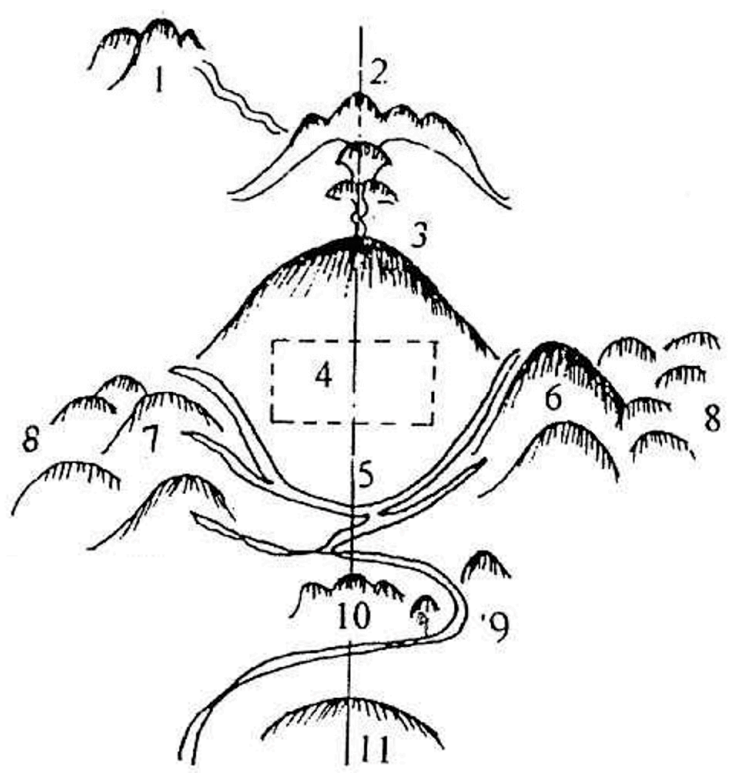

Figure 6. Selection of settlements by the Feng Shui principle. 
These preferences have been passed down to modern housing. During the 1970s' construction boom in Seoul, new south-facing apartments such as the Banpo Apartments, Ichon Apartments, and Apgujeong Apartments started being built along the Han River. Thus, the main configuration of apartment complexes on the south side of the Han River commands a southward, not a northward, view in general.

However, the perceived value of views is increasing compared to the value of the direction of building orientation. Housing that offers fine views of rivers or waterfronts is currently being constructed. The phrase "View Rights for the Han River" has recently appeared in the housing market in Seoul, suggesting that people prefer areas with excellent views, such as that of the Han River. Recent research suggests that if a building provides a favorable river view, people are less influenced by the building's direction [17-19]. In this case, the south-facing arrangement of housing for sunshine can be relinquished if there is more benefit to be obtained via landscape and waterfront views. However, this trade-off has not been confirmed by scientific analysis and remains a hypothesis.

These studies notwithstanding, no study has yet explored the correlation between apartment building layouts and stream flow direction [17-19]. Numerous factors, including the orientation and surrounding environment, determine the layout of an apartment. Thus, this study differs from previous research in its premise that the direction of stream flow greatly influences apartment building layouts in waterfront residential areas.

\section{Materials and Methods}

\subsection{Research Framework}

This survey was conducted for apartments near urban rivers to determine their relationships with respect to stream flow direction, followed by qualitative and quantitative analyses. Data were collected on apartment buildings in the vicinity of various branches of the Han River, including the west-flowing Yangjaecheon stream in Seoul and Gulpocheon stream in Incheon, as well as the north-flowing Anyangcheon stream, which is also located in Seoul. A total of 42 apartment buildings, across 19 apartment complexes, were surveyed along Yangjaecheon, together with 36 buildings from 13 apartment complexes along Gulpocheon and 119 buildings from 37 apartment complexes along Anyangcheon, as shown in Figure 7.

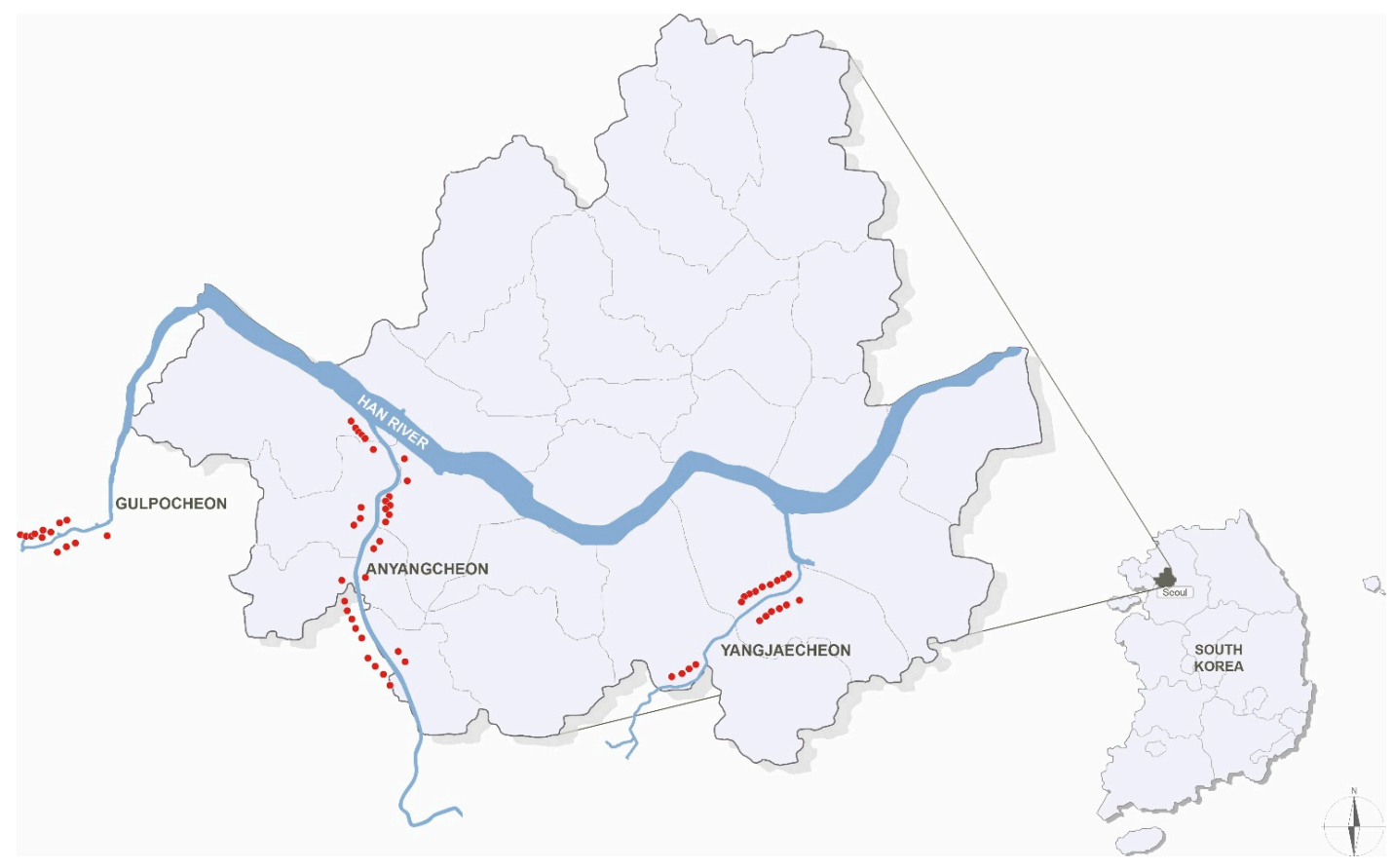

Figure 7. Study area: Southern Seoul. 
Using online geographic information system services such as Google Maps [20] (https://www. google.co.kr/maps/), Daum Maps [21] (http://map.daum.net/), and Naver Maps [22] (http://map.naver. $\mathrm{com} /$ ), an analysis of the location, orientation, layout, and type of the selected apartment buildings was conducted. Daum's real estate services site [23] (http://realestate.daum.net) was also used to obtain basic information, including the apartment complexes' address, year of construction, and number of buildings and floors, as well as the number of households. In addition, pictures were analyzed through field surveys and a time series urban image database. Findings were used to classify apartments according to orientation and layout, based on which patterns in the layouts of apartment buildings adjacent to the west- and north-flowing streams were analyzed.

A t-test analysis of the above findings was conducted to confirm whether flow directions of nearby streams influenced the apartment building layouts.

\subsection{Survey of Waterfront Apartment Building Layouts}

To ascertain the relationship between apartment building layouts and adjacent streams, the apartments in this study were classified into four categories of spatial configuration relative to the flow axes of adjacent streams: perpendicular, parallel, diagonal, and other.

With the side of the apartment where the living room is located as a basis, apartments were classified into three categories of orientation: east- and/or west-facing, south-facing, and other. If the side of an apartment with a living room fell within a $45^{\circ}$ angle east or west of the full south, the apartment was categorized as south-facing. The same formula was applied to classify east- and west-facing apartments. Flat- or mixed-type apartments with at least two orientations, or those whose orientations were difficult to determine, were classified as "other."

In line with the criteria defined above, a total of 197 apartment buildings were chosen from the apartment complexes along the west-flowing Yangjaecheon and Gulpocheon, as well as the north-flowing Anyangcheon, for the survey of apartment building orientations. The findings are presented in Tables 2 and 3, and Figures 8-10.

Table 2. Spatial relationships of apartment complexes around three major streams.

\begin{tabular}{crrrrrr}
\hline & \multicolumn{3}{c}{ West-Flowing Streams } & \multicolumn{2}{c}{ North-Flowing Stream } \\
\cline { 2 - 8 } & Yangjaecheon & \multicolumn{2}{c}{ Gulpocheon } & \multicolumn{2}{c}{ Anyangcheon } \\
\hline Perpendicular & 5 & $11.9 \%$ & 2 & $5.6 \%$ & $* 67$ & $* 56.3 \%$ \\
Parallel & $* 24$ & $* 57.1 \%$ & $* 25$ & $* 69.4 \%$ & 34 & $28.6 \%$ \\
Diagonal & - & - & 9 & $25 \%$ & 12 & $10.1 \%$ \\
Other & 13 & $31 \%$ & - & - & 6 & $5 \%$ \\
\hline Total & 42 & \multicolumn{3}{c}{36} & & 119 \\
\hline
\end{tabular}

${ }^{*}$ Highest numbers and percentages of spatial relationships of apartment complexes.

Table 3. Orientation of apartment buildings near major streams.

\begin{tabular}{ccccccc}
\hline & \multicolumn{3}{c}{ West-Flowing Streams } & \multicolumn{2}{c}{ North-Flowing Stream } \\
\cline { 2 - 6 } & Yangjaecheon & Gulpocheon & \multicolumn{2}{c}{ Anyangcheon } \\
\hline East or West & 5 & $11.9 \%$ & 2 & $5.6 \%$ & 40 & $33.6 \%$ \\
South & $* 24$ & $* 57.1 \%$ & $* 34$ & $* 94.4 \%$ & $* 72$ & $* 60.5 \%$ \\
Other & 13 & $31.0 \%$ & - & - & 7 & $5.9 \%$ \\
\hline Total & 42 & 36 & 119 \\
\hline \multicolumn{4}{c}{ * Highest numbers and percentages of apartment orientations }
\end{tabular}




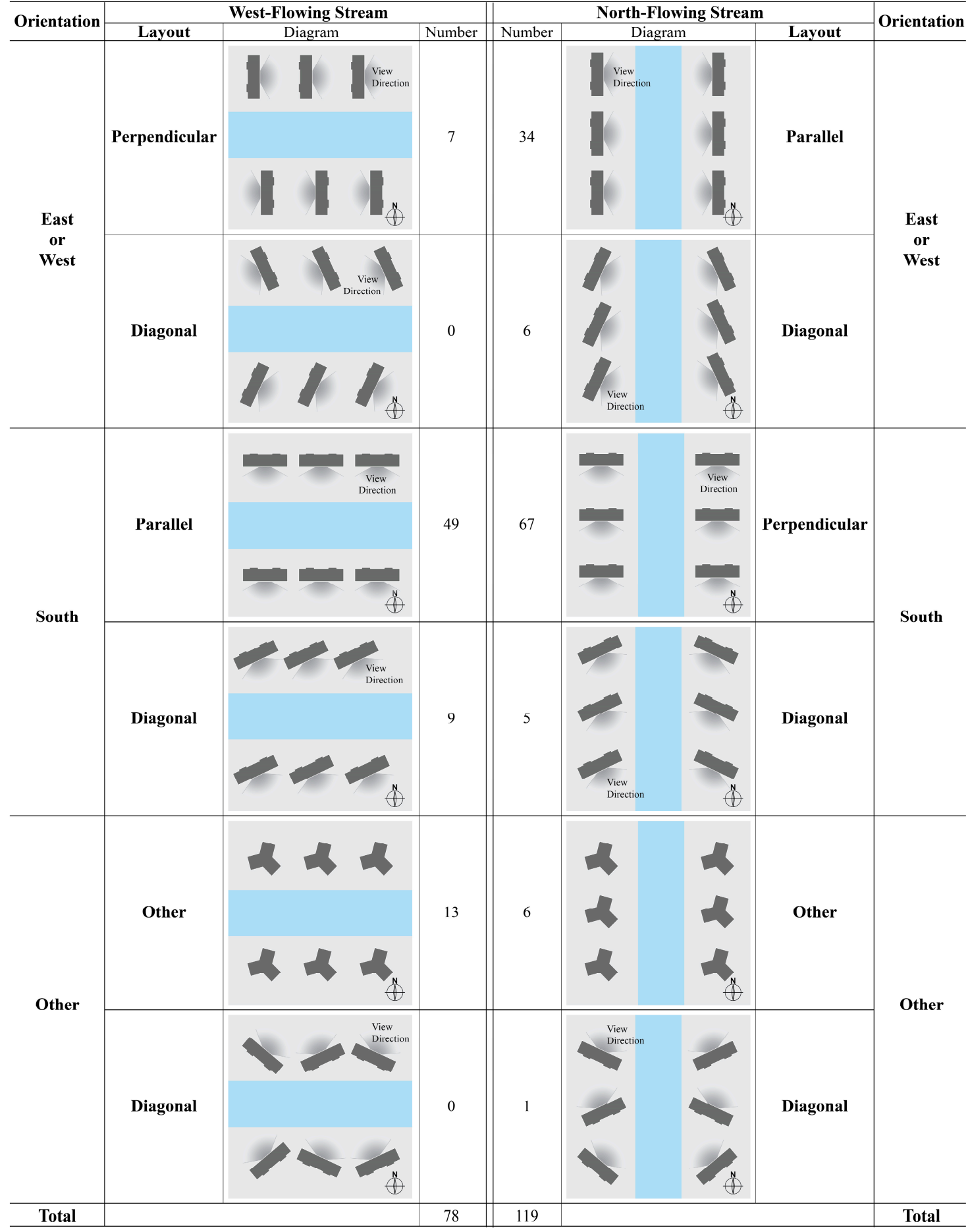

Figure 8. The relationship between housing layout and river direction. 


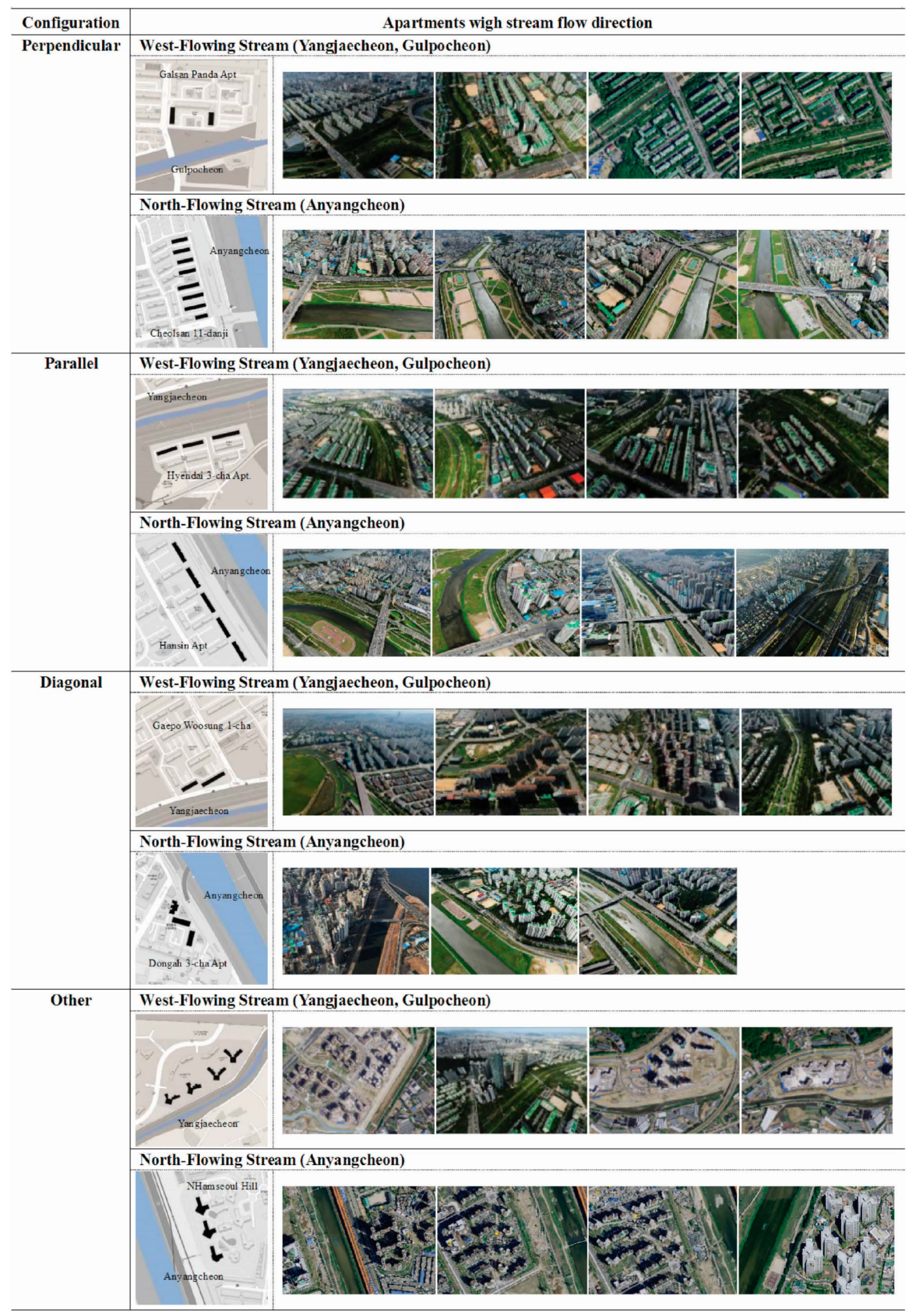

Figure 9. Spatial configuration and characteristics of apartments with respect to stream flow direction. 


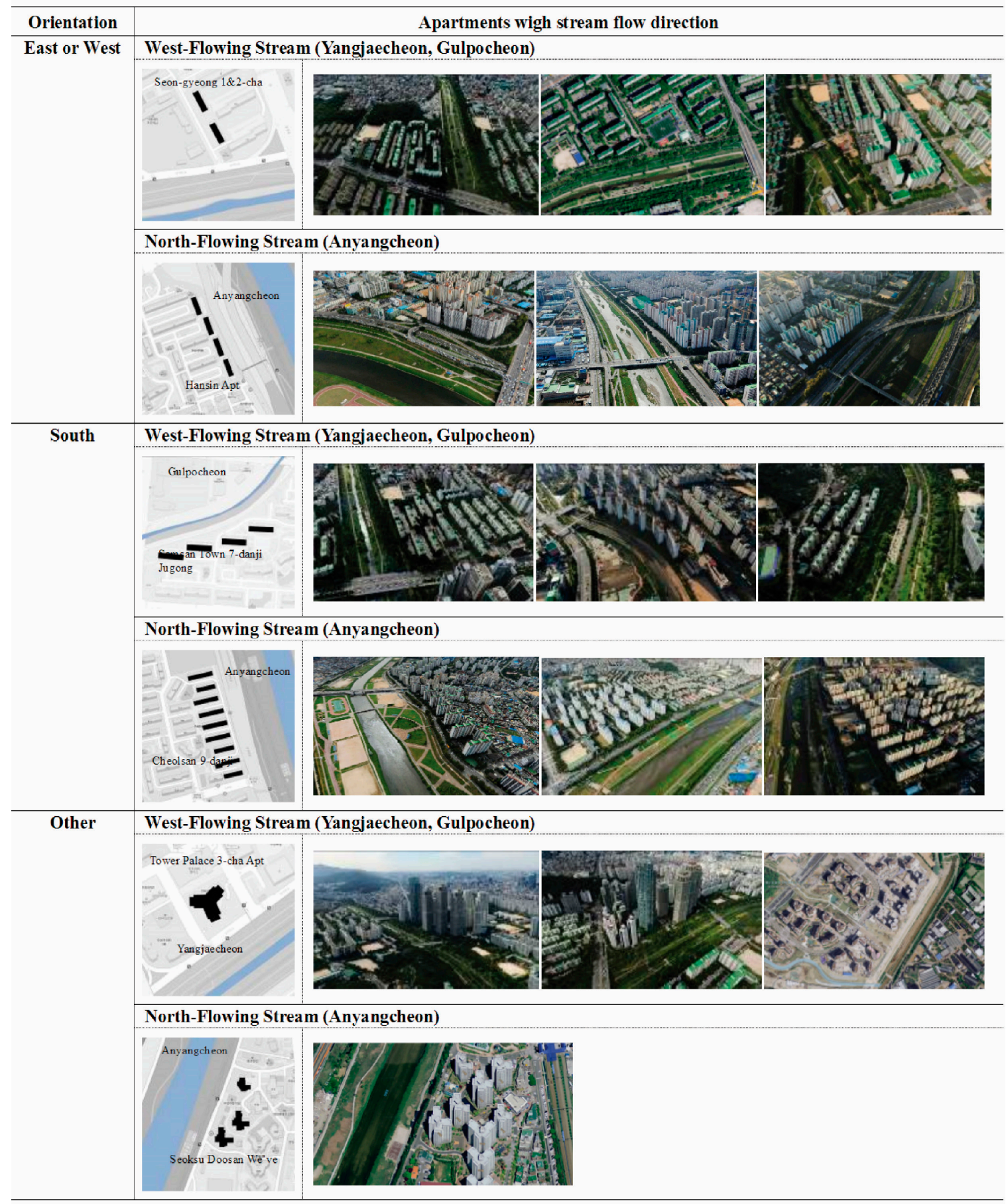

Figure 10. Orientation of apartment buildings near various streams.

\section{Results}

\subsection{Spatial Configuration of Apartments Relative to Adjacent Streams}

Classifying apartments based on their location relative to the flow axes of particular streams can help determine whether apartment configuration is affected by stream flow direction.

Apartments adjacent to west-flowing streams include the perpendicularly aligned Seon-gyeong 1-cha, Seon-gyeong 2-cha, Hyundai 2-cha, and Galsan Panda Apartments; the parallelly aligned Woosung 8-cha, Gyeongnam, and Doosan Apartments; and the diagonally aligned Sinseong Misojium Apartments. Apartments adjacent to the north-flowing Anyangcheon include the perpendicularly 
aligned Hyundai 1-cha and Miseong Apartments, the parallelly aligned Samsung Raemian and Woosung Apartments, and the diagonally aligned River Palace and Hyowon Villat Apartments (Figure 9).

For the west-flowing Yangjaedheon, it was found that the most prevalent type of configuration around the stream is the parallel configuration, with $57.1 \%$ of all apartments in the area sitting parallel to the stream. Tower-type apartments, classified here as "other," make up $31 \%$ of the total, while perpendicularly aligned apartments account for a significantly lower $11.9 \%$. Around Gulpocheon, the percentage of parallelly aligned apartments is particularly high at $69.4 \%$ of the total, while diagonally aligned apartments make up 25\%. Notably, perpendicularly aligned apartments comprise only $5.6 \%$ of the total. Around north-flowing Anyangcheon, perpendicularly aligned apartments are predominant, accounting for $56.3 \%$ of the total. Beyond these, $28.6 \%$ of all apartments are parallelly aligned, $10.1 \%$ are diagonally aligned, and only $5 \%$ can be classified as "other" (as indicated in Table 2).

Of the 119 apartment buildings situated around the north-flowing Anyangcheon, 67 apartment buildings are perpendicularly aligned, and approximately half that number are parallelly aligned. In contrast, 49 of the 78 buildings situated around the west-flowing Yangjaecheon and Gulpocheon are parallelly aligned, making this the predominant configuration in these areas. The perpendicular configuration, in comparison, is not so common here, with only seven buildings aligned in this way. Therefore, it was observed that the spatial configurations of apartment buildings differ with respect to west- and north-flowing streams.

\subsection{Stream Flow Direction and Building Orientation}

The relationship between the orientations of apartment buildings and stream flow directions was determined by classifying different apartments based on their orientations relative to the flow axes of particular streams. As seen in Table 6, the apartments in this study were classified into three categories of orientation: east- and/or west-facing, south-facing, and other. Overall, south-facing apartments were found to be predominant around west-flowing streams, corresponding to the general preference for south-facing homes. Although many south-facing apartments were also observed around the north-flowing stream, they comprise a markedly lower percentage of the total than apartments around west-flowing streams.

Situated around west-flowing streams are the east-facing Galsan Panda and east- and west-facing Hyundai 2-cha Apartments; south-facing Woosung 8-cha and LH Star Hills Apartments; and tower-type apartments, classified here as "other," such as the Tower Palace 1-cha Apartments. Around the north-flowing stream are the east-facing Hyundai 3-cha and east- and south-facing Mokdong Samsung Apartments, as well as the south-facing Cheolsan Apartments, 9-danji and 11-danji. Apartments classified as "other" include the Namseoul Hill State and Seoksu Doosan We've Apartments (Figure 10).

Of the 119 apartment buildings situated around the north-flowing stream, 72 face south; however, $33.6 \%$ (40 apartment buildings) face east/west. In contrast, 58 of the 78 total buildings situated around west-facing streams face south, making this the predominant orientation in these areas. Proportions of east- and west-facing buildings, in comparison, are much lower here. Buildings whose orientations are classified as "other" include tower-type or mixed-type apartments; around the west-flowing Yangjaecheon, these are mostly newer apartments built after 2000, in accordance with the trend of the growing diversification of apartment types. These apartments are more prevalent around the west-flowing streams than the north-flowing stream. Around the west-flowing Gulpocheon, however, where apartments are older, flat-type apartments are the most prevalent, and many of them face south (as indicated in Table 3).

\section{Discussion}

A t-test was conducted to confirm whether the ratio of the apartments parallel to the river is meaningful in each apartment complex adjacent to the river flowing west and north. In total, 32 apartment complexes are located near the west-flowing stream and 37 apartments are situated near 
the north-flowing stream. For the t-test, a continuous variable was set for each complex that faces each river directly, with the ratio of parallel or vertical alignment to the stream and the east/west-facing or south-facing ratio for the stream being established. This process assessed whether there is a meaningful difference between apartment layouts based on river direction.

According to the results, $73.4 \%$ of apartments in the apartment complex adjacent to the river flowing in the western direction are arranged parallel to the river, and $43.1 \%$ of the apartments in the apartment complex adjacent to the river running in the northern direction are parallel to the river. The $p$-value of 0.002 at the $95 \%$ confidence interval indicated statistical significance; that is, there are more parallelly aligned apartment buildings by the west-flowing stream than by the north-flowing stream (as indicated in Table 4).

Table 4. T-test for the proportion of parallelly aligned apartment buildings.

\begin{tabular}{ccc}
\hline & Near a West-Flowing Stream & Near a North-Flowing Stream \\
\hline Mean & 0.734 & 0.431 \\
Variance & 0.179 & 0.203 \\
Observations & 32 & 37 \\
Hypothesized mean difference & - & 0 \\
Degrees of freedom & - & 67 \\
t-Statistic & - & -2.873 \\
$\mathrm{P}(\mathrm{T} \leq \mathrm{t})$ one-tail & - & 0.003 \\
$\mathrm{t}$ Critical one-tail & - & 1.668 \\
$\mathrm{P}(\mathrm{T} \leq \mathrm{t})$ two-tail & - & 0.005 \\
t Critical two-tail & - & 1.996 \\
\hline
\end{tabular}

Next, we used a t-test to analyze the ratio of east-west or south-facing apartments of each apartment complex and determine whether there is a difference between east-west apartments according to the direction of the river.

First, $34.3 \%$ of east-facing apartments in the apartment complex are located adjacent to the north-flowing stream, but they rarely appear in the west-flowing stream $(7.8 \%)$. With a $p$-value of 0.001 at the $95 \%$ confidence interval, the relationship between the two proportions was found to be statistically significant. This shows that the proportion of east- and west-facing apartments is higher by the north-flowing stream than by the west-flowing streams (shown in Table 5).

Table 5. T-test for east-facing apartments.

\begin{tabular}{ccc}
\hline & Near a West-flowing Stream & Near a North-flowing Stream \\
\hline Mean & 0.078 & 0.343 \\
Variance & 0.052 & 0.196 \\
Observations & 32 & 37 \\
Hypothesized mean difference & - & 0 \\
Degrees of freedom & - & 55 \\
t-Statistic & - & 3.179 \\
$\mathrm{P}(\mathrm{T} \leq \mathrm{t})$ one-tail & - & 0.001 \\
t Critical one-tail & - & 1.673 \\
$\mathrm{P}(\mathrm{T} \leq \mathrm{t})$ two-tail & - & 0.002 \\
t Critical two-tail & - & 2.004 \\
\hline
\end{tabular}

Even more significant were the results for south-facing apartments, with $73.4 \%$ found near west-flowing streams and $48.8 \%$ near the north-flowing stream. This means that there are more south-facing apartments by west-flowing streams. Around the north-flowing stream, less than half of the apartments faced south. A $p$-value of 0.012 at the $95 \%$ confidence level indicated statistical significance $(p$-value $<0.5)$. This finding is particularly significant in the South Korean context, where south-facing apartments have long been preferred (as shown in Table 6). 
Table 6. T-test for south-facing apartments.

\begin{tabular}{ccc}
\hline & Near a West-Flowing Stream & Near a North-Flowing Stream \\
\hline Mean & 0.734 & 0.488 \\
Variance & 0.179 & 0.208 \\
Observations & 32 & 37 \\
Hypothesized mean difference & - & 0 \\
Degrees of freedom & - & 67 \\
t-Statistic & - & -2.326 \\
P(T $\leq \mathrm{t})$ one-tail & - & 0.012 \\
t Critical one-tail & - & 1.668 \\
P(T $\leq \mathrm{t})$ two-tail & - & 0.023 \\
t Critical two-tail & - & 1.996 \\
\hline
\end{tabular}

\section{Conclusions}

This study aimed to analyze the spatial configuration of apartments situated by streams with respect to stream flow direction. Accordingly, a survey was conducted for major streams in the Seoul metropolitan area, namely, the west-flowing Yangjaecheon and Gulpocheon rivers and the north-flowing Anyangcheon river.

The results indicate that south-facing apartments make up a higher percentage of the total around both west-flowing and north-flowing streams. However, the proportion of east-facing and west-facing apartments is higher by the north-flowing stream than by the west-flowing streams, and the proportion of south-facing apartments here is relatively lower. T-test analysis determined that these results are statistically significant. It was concluded that apartment building orientation is statistically correlated with apartment spatial configuration with respect to nearby streams. By the west-flowing Han River, for example, many apartment buildings face south, satisfying the general preference in Korea for orientation and view. Koreans traditionally favor the south, which receives more sunshine and natural ventilation. This preference has cultural origins in Feng Shui. In terms of apartment prices, south-facing apartments also trade at relatively high prices. In the case of the Han River flowing in the east-west direction, if the apartment arrangement is set to the south, having a river view is possible. On the other hand, in the case of rivers flowing in the north-south direction, when the housing arrangement of the apartment is made to the south, the view of the river must be relinquished. Currently, planners or developers have to choose between making a southward layout or facing the river. This study shows that the proportion of buildings with a river view is higher than those with a southward layout. These results suggest that the market's decisions and development have gradually moved from the preference for sunshine to that for landscapes or views.

This can be attributed to technological developments in housing that have facilitated improvement in heating and cooling facilities in residences. Such improvements have made it possible to obtain the same effects in houses facing other directions as those observed in south-facing residences. Moreover, as our planet has been becoming increasingly warmer in recent years, south-facing residences might lead to greater cooling costs during the summer.

This study focused on the relationship between housing layout and the direction of the river. However, there may also be other important factors at play. For example, the conditions of certain parts of the river view might not be so pleasant and thus be avoided. Noise, a foul smell, and dust might also affect the layout of the settlements. In addition to these neighborhood environmental factors, other factors include the cultural tradition of Feng Shui and broader environmental changes such as global warming. In addition, further analysis of the price of housing near the river and the environmental conditions of these apartment districts is needed. Moreover, the preferences of residents should be considered. Nonetheless, the findings of this study provide valuable information about the spatial configuration of waterfront apartments and provide a foundation for future studies looking to analyze the development of plans for waterfront residences. 
Many future designers and decision-makers can use this study's results to ascertain residents' needs. Technology and environmental conditions have been rapidly changing, and the relationship between waterfronts and human settlement may also change. The waterfront thus presents numerous possibilities for understanding the diversity of human settlements and their development over time.

Author Contributions: Conceptualization, Y.K.; Methodology, Y.K. and J.H.; Investigation, Y.S.

Funding: This research was supported by the Creative-Pioneering Researchers Program through Seoul National University (SNU). It received additional support from the Basic Science Research Program through the National Research Foundation of Korea funded by the Ministry of Education (2018R1D1A1B07048832). It was financially supported by Korea Ministry of Land, Infrastructure and Transport (MOLIT) as an Innovative Talent Education Program for Smart City.

Acknowledgments: This research was supported by Institute of Construction and Environmental Engineering at Seoul National University. The authors wish to express their gratitude for the support.

Conflicts of Interest: The authors declare no conflict of interest.

\section{References}

1. Hoyle, B.S.; Husain, M.S.; Pinder, D. Revitalising the Waterfront; John Wiley \& Sons Ltd.: New York, NY, USA, 1994.

2. Kostopoulou, S. On the revitalized waterfront: Creative milieu for creative tourism. Sustainability 2013, 5, 4578-4593. [CrossRef]

3. Shim, G. A Study on the Recognition of Housing Environments for Waterfront Area Users of Jungrangriverside. Master's Thesis, Graduate School of Housing, Seoul National University of Science and Technology, Seoul, Korea, 2011.

4. Kwon, Y.S.; Jo, M.S. A Study on the Urban Planning and Design Principles on Riverfront; Architecture and Urban Research Institute: Anyang, Korea, 2010.

5. City of Seoul. The Masterplan of Hangang Renaissance; City of Seoul: Seoul, Korea, 2007.

6. Lee, Y.H.; Lee, H.J. A study on the residents' using behavior of the waterside in the waterfront apartment complex. J. Archit. Inst. Korea Plan. Des. 2003, 19, 31-38.

7. Lee, K.T.; Lee, J.Y. A study on analysis of view-character of apartment site near waterfront of River Nakdong as urban image. J. Archit. Inst. Korea Plan. Des. 2001, 17, 261-272.

8. Yoon, J.W.; Park, S.W.; Jeong, T.Y. Determinants of apartment prices in Busan: A spatial quantile regression. Manag. Inf. Syst. Rev. 2018, 37, 155-175.

9. Gelezeau, V. Séoul, Ville Géante, Cités Radieuses, 10th ed.; Humanitasbook: Seoul, Korea, 2007.

10. Jung, S.J.; Yoon, S.H. Changes in Sunlight and Outdoor Thermal Environment Conditions Based on the Layout Plan of Flat Type Apartment Houses. Energies 2015, 8, 9155-9172. [CrossRef]

11. Choi, J.P.; Kim, Y.W.; Kang, J.K.; Choi, Y.J. Comparative Analysis of the Spatial Structure of Apartment Unit Plans in Asia-Apartments in Korea, Vietnam, and Kazakhstan. J. Asian Archit. Build. Eng. 2014, 13, 563-569. [CrossRef]

12. Statistics Korea (KOSTAT). Available online: http://kostat.go.kr/ (accessed on 21 November 2016).

13. Jang, L.J.; Park, J.H. Explorations into the First-Generation Apartments in Korea; Hyohyung: Seoul, Korea, 2009.

14. Jeong, S.K.; Ban, Y.U. The spatial configurations in South Korean apartments built between 1972 and 2000. Habitat Int. 2014, 42, 90-102. [CrossRef]

15. Krieger, A.; Fisher, B.; Gordon, D.L.A. Remaking the Urban Waterfront; Urban Land Institute: Washington, DC, USA, 2004.

16. Watson, D.; Adams, M. Design for Flooding: Architecture, Landscape, and Urban Design for Resilience to Flooding and Climate Change; John Wiley and Sons: Hoboken, NJ, USA, 2011.

17. Park, S.Y.; Lee, D.J.; Choi, M.H. A comparative analysis of the orientation and view value through the layout analysis of the apartment buildings at river-front in city area-Focused on the apartments at Shin-Chon River-front in Dae-gu. J. Archit. Inst. Korea Plan. Des. 2006, 18, 41-48.

18. Lee, D.J.; Choi, M.H. An analytic study on the value comparison orientation with view through the consciousness investigation of occupants living at apartment-Focused on the confrontational relation between orientation and view. J. Archit. Inst. Korea Plan. Des. 2006, 22, 87-94. 
19. Song, D. A study on the characteristic analysis of the landscape preference to arranged type of located high-rise apartments at the street. J. Archit. Inst. Korea Plan. Des. 2002, 17, 111-120.

20. Google Map. Available online: https://www.google.co.kr/maps/ (accessed on 4 April 2016).

21. Daum Map. Available online: http://map.daum.net/ (accessed on 4 April 2016).

22. Naver Map. Available online: http://map.naver.com/ (accessed on 4 April 2016).

23. Daum's Real Estate Services Site. Available online: http://realestate.daum.net/ (accessed on 4 April 2016).

(C) 2019 by the authors. Licensee MDPI, Basel, Switzerland. This article is an open access article distributed under the terms and conditions of the Creative Commons Attribution (CC BY) license (http://creativecommons.org/licenses/by/4.0/). 